\title{
A SUSTENTABILIDADE EMPRESARIAL COMO VANTAGEM COMPETITIVA EM BRANDING
}

\section{SUSTAINABILITY AS BUSINESS ADVANTAGE COMPETITIVE IN BRANDING}

Larissa Fontoura Berlato ${ }^{1}$

Fabiane Saussen ${ }^{2}$

Luiz Salomão Ribas Gomez $z^{3}$ 


\section{Resumo}

A sociedade atual necessita de uma mudança de paradigmas a ser posta em prática pelos cidadãos, empresas e governos. Faz-se necessário rever nosso modo de vida e reinventar os modelos de produção e de consumo, conciliando as dimensões econômica, ambiental e social, para que as empresas prosperem e nosso futuro tenha garantia. A sustentabilidade como prática no setor empresarial, além de contribuir para melhorias no meio ambiente e para a construção de uma sociedade mais justa, possibilita novas políticas de estratégia em branding. Este trabalho, objetiva evidenciar a sustentabilidade empresarial como uma oportunidade para novas estratégias em branding. Inicialmente, o presente artigo analisa os conceitos de desenvolvimento sustentável e de sustentabilidade empresarial e seu uso como estratégia em branding. Por fim, apresenta duas empresas que fazem uso da sustentabilidade em branding e estabelece relações entre o uso da sustentabilidade e seus benefícios para a marca e para perenidade das empresas.

Palavras-Chave: Desenvolvimento sustentável. Empresas. Gestão de marcas.

\section{Abstract}

The setting of the current society needs a paradigm shift on the part of citizens, businesses and governments. It is necessary to review our way of life and reinvent the models of production and consumption, reconciling the economic, environmental and social dimensions in business, for the prosperity of the companies and our future. Sustainability as a practice in the business sector, in addition of contributing to improvements in the environment and building a more just society, enables new political positioning and branding strategy. This work, aims to analyze the relationship between corporate sustainability in branding as a competitive advantage and prosperity. Thus, the article first analyzes the concepts of sustainable development, corporate sustainability and its use as a strategy in branding. Finally, indicates companies that make use of sustainability in branding and establishes connections between the use of sustainability and its benefits to the brand and the success of companies.

Keywords: Sustainable development. Companies. Brand management. 


\section{INTRODUÇÃO}

Os modelos de produção e consumo utilizados desde a Revolução Industrial, bem como os valores que os sustentam, estão em desacordo com as bases necessárias para a manutenção de um ambiente sadio pois vêm comprometendo o futuro do nosso planeta. A crescente extração dos recursos naturais tem gerado impactos avassaladores na sociedade e no meio ambiente. Junta-se a isso uma crise econômica mundial que vem aumentando os níveis de pobreza e de desemprego em diversos países, inclusive nos considerados de Primeiro Mundo.

\footnotetext{
"A presente década tem sido marcada por preocupações sociais. Os cientistas chamam atenção para problemas urgentes e complexos que comprometem a nossa própria sobrevivência. Como parte do nosso "desenvolvimento", temos acumulado arsenais capazes de desviar o caminho que a evolução tem seguido por milhões de anos e de criar um planeta que nossos antepassados não reconheceriam.” (BRUNDTLAND, 1987, p.13)
}

Tendo em mente que os recursos naturais são finitos e que, no modelo econômico atual, as empresas exercem grande influência sobre os recursos humanos, sociais e ambientais, o desenvolvimento sustentável como prática na sociedade e no mundo corporativo é essencial para a melhoria da qualidade de vida de todos. Esse cenário econômico, social e ambiental está gerando transformações na sociedade, e o tema sustentabilidade está crescendo em importância não somente para os cidadãos como também para as empresas.

"O consumidor atual demanda abordagens de marketing mais colaborativas, culturais e espirituais. As empresas devem se mostrar socialmente responsáveis, somente dessa forma elas terão consumidores comprometidos e engajados." (KOTLER, KARTAJAYA E SETIAWAN, 2010, p.22)

A prática da sustentabilidade nas empresas é uma visão estratégica a longo prazo que possibilita novas políticas de posicionamento e estratégia em branding, que podem resultar em vantagem competitiva frente a um mercado de concorrência acirrada e de produtos e serviços similares no qual as empresas vêm-se obrigadas a buscar outros pontos de diferenciação.

Este trabalho tem como principal objetivo evidenciar a sustentabilidade empresarial como uma oportunidade para novas estratégias em branding, enquanto avalia a influencia da adoção de práticas de sustentabilidade nas empresas para o sucesso no âmbito mercadológico, filosófico e financeiro. Além disso, aborda as diferenças entre uma empresa que tem a sustentabilidade em seu próprio DNA, como propósito principal, a Whole Foods, e outra, que adota a sustentabilidade de forma tática, em algumas práticas e ações, a Ypê.

Como procedimento metodológico, foi realizado um estudo exploratório acerca dos pressupostos teóricos que envolvem as temáticas de sustentabilidade, desenvolvimento sustentável, sustentabilidade empresarial e branding. Além disso, foi pesquisado o modo como as empresas estão se utilizando da sustentabilidade empresarial em branding como uma oportunidade de negócio. $O$ delineamento desse 
estudo foi feito por meio de uma pesquisa bibliográfica em livros, revistas, artigos científicos e dados provenientes de institutos de pesquisa. 


\section{A NECESSIDADE DE MUDANÇA PARA UM DESENVOLVIMENTO SUSTENTÁVEL}

A Era Industrial marca o início do desenvolvimento do capitalismo industrial, do crescimento da produção em massa e do surgimento de novas populações urbanas. Esse modelo econômico não estava atento aos impactos adversos do que se produzia e consumia. Por um lado, as empresas tendo como único objetivo a minimização dos custos e a maximização dos lucros e, por outro, o surgimento de uma ideologia consumista na sociedade.

De acordo com Manzini (2006, p.2), a noção de bem-estar nas últimas décadas foi associada ao poder de consumo que se fez sentir nas sociedades desenvolvidas, promovido pelos avanços tecnológicos e científicos, proporcionando uma panóplia de novos tipos de produtos que ao longo do tempo foram sendo integrados na sociedade transmitindo uma melhoria constante da qualidade de vida. $O$ alto consumo de produtos e serviços, que não tinham sido projetados com a consciência que nos dias de hoje se procura incessantemente implementar, responsabilizando em grande parte os seus autores e quem os comissiona pelos impactos ambientais e sociais globais.

Complementando, acrescenta-se o que diz Castells (1999, p.141), "a maioria de nossos problemas ambientais mais elementares ainda persistem, uma vez que seu tratamento requer uma transformação nos meios de produção industriais e de consumo, bem como de nossa organização social e de nossas vidas pessoais."

Segundo Barbieri et al (2010, p.149), "na sociedade atual, os valores ligados ao desenvolvimento sustentável e ao respeito às políticas ambientais têm sido institucionalizados em maior ou menor grau nos diversos países pela mídia, pelos movimentos sociais e ambientalistas, e pelos governos."

Pinheiros (2006) defende que, a responsabilidade pelo desenvolvimento sustentável do planeta está repartida entre governos, organizações e sociedade. $O$ autor ressalta a importância do papel das empresas, visto que possuem recursos financeiros e tecnológicos, além de competência institucional e visão de longo prazo para solucionar seus problemas ambientais. Os governos têm contribuído por meio de novas políticas sociais e de preservação do meio ambiente, bem como com a criação de regulamentação e fiscalização nessas áreas.

A respeito do comportamentos de quem consome, afirmam Kotler, Kartajaya e Setiawan (2010, p.4): "cada vez mais, os consumidores estão em busca de soluções para satisfazer seu anseio de transformar o mundo globalizado num mundo melhor. Em um mundo confuso, eles buscam empresas que abordem suas mais profundas necessidades de justiça social, econômica e ambiental em sua missão, visão e valores. Buscam não apenas satisfação funcional e emocional, mas também satisfação espiritual nos produtos que escolhem."

O contexto atual possibilita uma nova dinâmica para o mundo, que revê nosso modo de vida e reinventa os modelos de produção e de consumo, conciliando as dimensões econômica, ambiental e social nos negócios com a prosperidade das empresas e a preservação de nosso futuro em uma sociedade mais justa e sustentável. 


\section{SUSTENTABILIDADE E DESENVOLVIMENTO SUSTENTÁVEL}

Foi a partir do relatório "Nosso futuro comum", que a expressão "Desenvolvimento sustentável" ganhou notoriedade (BRUNDTLAND, 1987). Esse documento foi a base das discussões da Conferência das Nações Unidas para o Meio Ambiente e o Desenvolvimento (CNUMAD), mais conhecida como ECO 92 ou RIO 92, uma conferência promovida pela ONU no Rio de Janeiro, em 1992. O principal objetivo deste encontro foi o incentivo à mobilização das nações mundiais para a formulação e integração de um plano de ação visando impulsionar a criação de novas políticas governativas, focando em especial a consideração da proteção ambiental como princípio de desenvolvimento e a sensibilização para os padrões insustentáveis de consumo e produção nos países industrializados (UNDSD, 1992).

Desenvolvimento sustentável, de acordo com o Relatório Bruntland (1987, p.24) é o desenvolvimento que procura satisfazer as necessidades da geração atual, sem comprometer a capacidade das gerações futuras de satisfazer as suas próprias necessidades. Isso significa possibilitar que as pessoas, agora e no futuro, atinjam um nível satisfatório de desenvolvimento social e econômico e de realização humana e cultural, fazendo, ao mesmo tempo, um uso razoável dos recursos da terra e preservando as espécies e os habitats naturais. $O$ relatório também propõem uma atuação conjunta dos governos, empresas e sociedade na busca de soluções sustentáveis.

Para Barbieri et al (2010, p.147): "o movimento pelo desenvolvimento sustentável parece ser um dos movimentos sociais mais importantes deste início de século e milênio. São incontáveis as iniciativas voluntárias relacionadas ao desenvolvimento sustentável por parte das empresas, bem como as elaborações de cartas de princípios e diretrizes de ação."

Segundo Sachs (2002), para que haja desenvolvimento sustentável é necessário o cumprimento da satisfação das necessidades básicas, solidariedade com as gerações futuras, participação da população envolvida, preservação dos recursos naturais e do meio ambiente, elaboração de um sistema social que garanta emprego, segurança social e respeito a outras culturas, e programas de educação.

O desenvolvimento sustentável busca um equilíbrio entre o crescimento econômico, a equidade social e a proteção do meio-ambiente, o chamado Tripé da Sustentabilidade. 


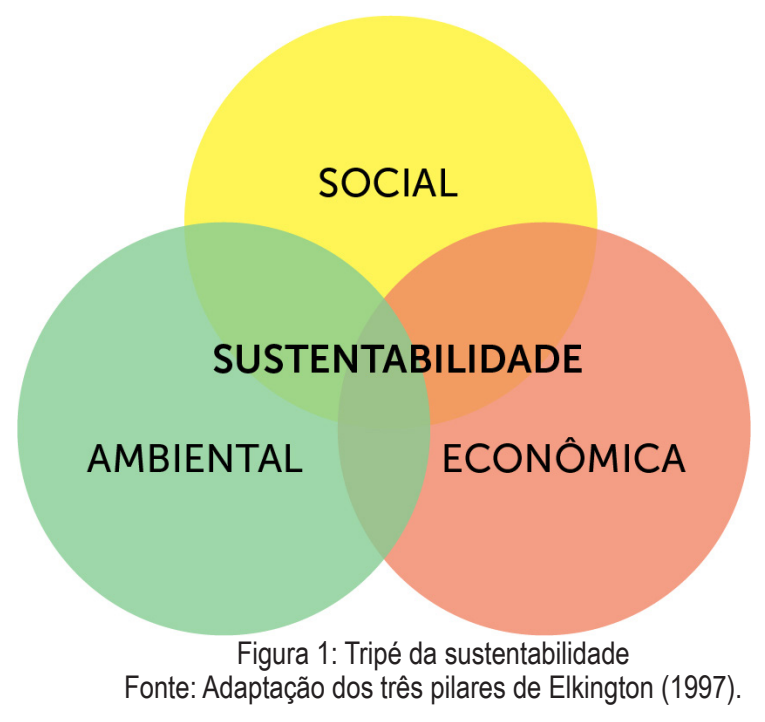

\section{SUSTENTABILIDADE EMPRESARIAL}

O Instituto Ethos de Empresas e Responsabilidade Social defende que um negócio sustentável gira em torno de uma atividade econômica orientada para a geração de valor econômico-financeiro, ético, social e ambiental, cujos resultados são compartilhados com os públicos afetados.

De acordo com Almeida (2002) uma empresa para ser sustentável deve buscar em todas as suas ações e decisões a ecoeficiência, procurando produzir mais e com melhor qualidade, gerando menos poluição e utilizando menos recursos naturais. A empresa deve ainda ser socialmente responsável, assumindo que está imersa num ambiente social em que influi ao mesmo tempo em que sofre influência. A motivação dos líderes empresariais deve ser respaldada numa visão de longo prazo, em que se leve em consideração os custos futuros e não somente os custos presentes.

A sustentabilidade empresarial significa entender e agir em resposta a essa nova demanda da sociedade, que é a de que o valor gerado por uma empresa se reflita em benefícios não somente para seus acionistas, mas que tenha também um impacto positivo para o conjunto dos afetados por suas operações, em particular o meio ambiente e a comunidade, respeitando sua cultura e agindo de forma ética e transparente.

Dessa forma, uma empresa sustentável deve estar atenta as suas ações em todas as dimensões do desenvolvimento sustentável: econômica, social e ambiental. Esse tipo de gestão deve considerar o resultado de suas atividades para com todos os stakeholders: funcionários, fornecedores, consumidores, investidores, concorrentes, governo e comunidade.

Barbiere et al (2010, p.148) afirmam que: "o crescimento econômico é algo sempre desejado e perseguido por empresários e políticos, o que explicaria a grande adesão que eles deram ao movimento de sustentabilidade."

O objetivo primordial da empresa continua sendo o lucro, base fundamental da 
sua existência. Entretanto, o uso do desenvolvimento sustentável como estratégia de negócio faz com que a empresa concilie as questões sociais e ambientais com os seus resultados financeiros. O sucesso da empresa não está mais ligado somente a sua capacidade de produção, mas também a sua participação mais ampla na sociedade, nas esferas sociais e ambientais. Os relatórios corporativos passaram a incluir o triple bottom line, no qual os resultados de uma empresa são medidos em termos sociais, ambientais e econômicos.

De acordo com Barbiere et al (2010), incentivar a inovação da gestão na sustentabilidade corporativa está diretamente relacionado com a competitividade futura do negócio, sendo necessário, por parte da organização, um acompanhamento por meio dos indicadores sustentáveis, compondo essa uma nova prática organizacional.

As empresas que integram a sustentabilidade à sua estratégia de negócios conseguem vantagens competitivas significativas como redução de custos e incremento nos lucros a médio e longo prazo, aumento de produtividade, melhora da imagem de marca, aumento do valor de marca, conquista de novos públicos e fidelização de clientes.

Uma pesquisa global, realizada pela empresa de relações públicas Edelman (2007), com 5.600 pessoas em nove países, afirma que $85 \%$ dos consumidores preferem marcas socialmente responsáveis, $70 \%$ estariam dispostos a pagar mais por essas marcas e $55 \%$ responderam que inclusive ajudariam a promovê-las.

\section{BRANDING}

\footnotetext{
"Branding é o conjunto de ações ligadas à administração das marcas. São ações que, tomadas com conhecimento e competência levam as marcas além da sua natureza econômica, passando a fazer parte da cultura, e a influenciar a vida das pessoas." (MARTINS, 2006, p.8).
}

Branding pode ser entendido como um conjunto de técnicas e ferramentas ligados à criação, ao desenvolvimento, à experiência e à gestão de uma marca.

$\mathrm{Na}$ economia atual, de competição acirrada, os produtos e serviços que fazem sucesso são rapidamente copiados. Além disso, há uma forte terceirização da produção no exterior, o que resulta em componentes e técnicas iguais para todos os concorrentes. Os consumidores, que estão cada vez mais informados, começam a considerar os produtos e serviços como commodities, aumentando a necessidade das empresas de se diferenciarem. Dessa forma, o branding é uma importante ferramenta de gestão de uma marca, que busca gerar valor agregado, tendo, como objetivo principal, a criação e a potencialização das percepções acerca dessa marca, fundamentada principalmente na cultura, na visão e nos valores da empresa.

"O valor de uma marca vem de sua habilidade em ganhar um significado exclusivo, destacado e positivo na mente dos clientes." (Kapferer, 1992, p.16) 
Uma marca deve ter um propósito autêntico e único. O propósito é o modo como a empresa pretende contribuir com a humanidade, a razão de sua existência. Uma marca com propósito significativo tem uma proposta de valor, uma verdadeira diferenciação e, dessa forma, consegue envolver o consumidor em um sentimento de significado maior e de valores partilhados.

Pine e Gilmore (2007, apud KOTLER, KARTAJAYA E SETIAWAN, 2010, p.39) argumentam que, "hoje, quando os consumidores veem uma marca, avaliam imediatamente se ela é falsa ou verdadeira. As empresas devem sempre tentar ser verdadeiras e proporcionar experiências que representem de fato suas alegações."

A autenticidade é fundamental para as marcas. A autenticidade se estabelece na medida em que os valores que uma empresa projeta se alinham bem com a realidade de suas ações. Os princípios e valores estabelecidos devem ser praticados no dia-a-dia da empresa e orientar todo o trabalho desenvolvido pela marca. Empresas se destacam pela excelência da qualidade e desempenho de seus produtos e serviços mas cada vez mais se destacam pela credibilidade, confiança e postura ética.

Holt (2002) acredita que as marcas percebidas como artificiais encontrarão dificuldades para se manterem bem sucedidas. Ao mesmo tempo, as marcas que forem genuínas e significativas ganharão níveis de importância sem precedentes.

\footnotetext{
"Outra característica geral importante das marcas é que elas podem realmente existir no domínio público. Num certo sentido, ser consumidor de uma marca específica é como ser sócio daquele "clube" da marca. Como o ato de compra e uso da marca é em muitos casos um consumo visível, o ato tem claras implicações para a personalidade do comprador. Assim, cada vez que um cliente usa uma marca, ele está reafirmando sua simpatia por aquilo que a marca representa em termos de promessa." (PRINGLE E THOMPSON, 2000, p.50)
}

A personalidade da marca pode vir a completar a personalidade do consumidor, visto que o consumo é um ato em que as pessoas buscam elementos que podem compor a imagem que desejam projetar de si mesmas. O consumo de uma determinada marca reflete o espaço de idealização do consumidor, a maneira como ele quer ser visto na sociedade.

Ao comprar e consumir produtos e serviços, os consumidores compram a felicidade e a auto-realização e não apenas os atributos funcionais. Nesse sentido, Kotler, Kartajaya e Setiawan (2010, p.42) afirmam que "o valor da marca deve apelar para as necessidades e os desejos emocionais dos consumidores, ultrapassando assim, as funcionalidades e características dos produtos."

No cenário atual, as marcas precisam se engajar com seus consumidores, partilhando com eles os mesmos anseios e desejos. Segundo Arvidsson (2008, LEHNER e HALLIDAY, 2014, p.14): "a base do poder é a capacidade de criar uma comunidade, o que faz com que as pessoas sintam que pertencem a algo maior, mais nobre e mais poderoso do que elas mesmas." 


\section{SUSTENTABILIDADE EMPRESARIAL COMO ESTRATÉGIA EM BRAN- DING}

De acordo com um estudo feito pelo Instituto Akatu (2009), o consumidor consciente tem como principal característica a análise crítica feita no momento da escolha de consumo no que se refere aos impactos socioambientais que o seu ato de compra, de uso ou descarte de um produto ou serviço pode vir a causar. Nesse sentido, ele procura equilibrar suas necessidades pessoais com as necessidades da sociedade e as possibilidades do planeta.

O consumidor consciente encontra-se dividido entre os impulsos consumistas e o impacto negativo que seu comportamento de consumo pode ter sobre a sociedade e o planeta. Muitas vezes, as necessidades e os padrões de consumo dos consumidores atuais vão contra as aspirações e os valores do espírito humano. O consumo mais consciente, ético e responsável é a opção para os consumidores que desejam transformar o mundo em um lugar melhor e mais justo. Assim, o consumo de marcas sustentáveis permite satisfazer os desejos consumistas, diminuindo o sentimento de culpa do consumidor e refletindo a maneira como ele quer ser visto na sociedade.

No que se refere ao posicionamento de marcas verdes, podemos estabelecer uma abordagem funcional, que se dirige para a racionalidade, porque disponibiliza informações detalhadas sobre os benefícios ambientais do produto e uma abordagem emocional, que destaca benefícios relacionados às necessidades emocionais das pessoas, tais como a sensação de satisfação ao contribuir para a melhoria e a proteção do meio-ambiente, ou para ostentar aos outros uma consciência ambiental. (Hartmann, Apaolaza Ibáñez e Forcada Sainz, 2005, p.9).

A estratégia mais efetiva de sustentabilidade em branding é a criação de apelos emocionais, amparados por informações funcionais claras, precisas e mensuráveis sobre os benefícios sustentáveis do produto ou serviço. Ao adquirir um produto ou serviço de uma empresa responsável social e ambientalmente, o consumidor tende a ampliar o valor de sua satisfação, o que confere à marca e à empresa uma reputação acima da média. Por isso, muitas empresas já vêm fazendo esforços nesse sentido, inovações em produtos e serviços ecofriendly, processos ecoeficientes, bem como parcerias com órgãos governamentais e não-governamentais.

De acordo com a pesquisa da Edelman, já citada, a maioria dos entrevistados (57\%) não tem restrições com marcas que apoiem causas sociais e ambientais e lucrem ao mesmo tempo. Os consumidores entrevistados afirmaram que, ao escolher entre duas marcas com o mesmo preço e qualidade, uma marca com um propósito sustentável é mais importante do que o design ou a fidelidade à marca.

Oferecer produtos com qualidade e desempenho que satisfaçam os seus consumidores já não é mais o suficiente para conquistar e fidelizar clientes. O comportamento do consumidor, antes baseado apenas em preço e qualidade dos produtos, hoje valoriza os aspectos emocionais e as aspirações espirituais das marcas. Por isso, as empresas precisam desenvolver valores apropriados para conquistar os novos consumidores que se sensibilizam com apelos altruístas. Uma empresa, ao se posi- 
cionar no mercado como comprometida com as questões sociais e ambientais, faz da sua imagem o seu principal fator de competitividade, valorizando seus produtos e serviços e sua marca.

Para que as empresas tenham o reconhecimento dos seus esforços em termos de sustentabilidade é necessária uma visão de longo prazo, focada em questões significativas, que tragam benefícios reais para a sociedade e para o ambiente. As empresas comprometidas são coerentes e atuam com transparência e honestidade, utilizando-se de práticas reais e mensuráveis e comunicando suas ações e atitudes de forma clara e objetiva. As marcas que observam essas premissas conquistam admiração e engajamento dos consumidores, estabelecendo uma relação na qual tanto a empresa quanto a sociedade se beneficiam.

Segundo Barbiere e Cajazeira (2009), não basta se vender como sustentável e não ter atos condizentes com essa ideia. O reconhecimento da importância da sustentabilidade empresarial tem levado algumas empresas a praticarem o fenômeno chamado green washing, que ocorre quando a empresa promove seu produto ou serviço como ecoeficiente, mas, na verdade, seus méritos ecológicos são apenas aparentes ou as informações dadas são parciais e não totalmente verdadeiras, causando uma imagem distorcida na mente do consumidor. Manipular o consumidor com inverdades enfraquece a marca e resulta em perda de credibilidade, o que prejudica a sua reputação e a sua imagem.

As empresas que integram a sustentabilidade à sua estratégia em branding de forma eficaz e verdadeira conseguem vantagens competitivas significativas como melhora da imagem de marca, aumento do seu valor, fidelização de seus clientes e conquista de novos públicos.

\section{INICIATIVAS DE SUSTENTABILIDADE EMPRESARIAL E SEUS BENE- FÍCIOS EM BRANDING}

\section{Rede de supermercados Whole Foods Market, sustentabilidade como propósito.}

A Whole Foods Market é uma rede de supermercados norte-americana especializada em produtos orgânicos e alimentação saudável. A empresa é considerada um dos maiores fenômenos do varejo mundial, faturando quase 13 bilhões de dólares em 2013.

Segundo o Whole Foods Green Mission Report, entre seus valores fundamentais estão a venda de produtos naturais e orgânicos de alta qualidade, a satisfação dos clientes, a excelência, a felicidade da equipe, a criação de valor por meio do lucro e do crescimento, o apoio à comunidade e o envolvimento local e a promoção e o cuidado com o meio-ambiente.

O Whole Foods Market por meio de padrões de compra, iniciativas de rotulagem e educação, promove a produção local, as práticas de agricultura sustentável, a melhora da agropecuária e a prática de pesca responsável. 
Cada loja tem uma equipe da Missão Verde, que ajuda a coordenar programas sustentáveis como programas de reciclagem, de compostagem e de substituição de sacolas plásticas. A empresa tem implementado atualizações de eficiência energética e utilizado materiais, sistemas de construção e arquitetura ecologicamente corretos nas suas lojas e escritórios.

A Whole Foods Market's Local Producer é um programa de empréstimo para pequenos produtores locais, a juros mais baixos e com menos burocracia do que é oferecido pelos bancos tradicionais.

O Whole Planet Foundation oferece doações para as organizações parceiras que operam nas áreas de microfinanças em comunidades de países em desenvolvimento que fornecem produtos para a rede.

O Whole Kids Foundation visa a apoiar as escolas e a inspirar as famílias a melhorar a nutrição e o bem-estar das crianças, bem como a contribuir com a diminuição da obesidade infantil.

A partir dos dados expostos, podemos constatar que a sustentabilidade nessa empresa não é feita a partir de ações isoladas, mas é o seu propósito principal, parte essencial de seus valores, feita de práticas mensuráveis que se referem ao seu negócio. A Whole Foods Market tem criado valor para a sua marca através da sustentabilidade como estratégia em branding, com um propósito significativo e de grande apelo.

A marca comunica-se com os consumidores de forma clara e objetiva, informando-os sobre seus produtos, serviços, processos e programas sustentáveis. Isso estabelece uma relação de transparência com seus consumidores e funcionários e gera confiança e credibilidade com seus fornecedores. Com essas atitudes, ela fortalece seu relacionamento com os consumidores, resultando em maior lealdade à marca.

A Whole Foods Market sensibiliza os consumidores ao informar a procedência dos produtos que eles estão comprando. A empresa comunica de onde eles vêm, como são feitos e quem os fez. Assim a marca torna-se humanizada e com forte apelo emocional.

A marca é autêntica e atrativa, apoia-se em um propósito significativo e cumpre sua promessa. Tudo o que permeia seus produtos, serviços e suas atitudes tem coerência e consistência. Ela é capaz de entregar os benefícios realmente desejados pelos clientes.

O branding da Whole Foods Market utiliza um repertório de ações que criam valor, vendendo um bem-estar subliminar aos consumidores, permitindo-lhes fazer parte de um propósito maior, o que gera o sentimento de pertencimento que o consumidor pós-moderno tanto anseia.

A campanha publicitária Values Matter informa o pioneirismo da empresa na indústria de alimentos orgânicos e reitera o propósito significativo da empresa. A iniciativa tem como objetivo, destacar-se frente à concorrência crescente no mercado orgânico, associando a marca a sinônimo de qualidade e produção de alimentos de forma humana, sustentável e práticas trabalhistas justas, atraindo e fidelizando os consumidores éticos e conscientes.

A estratégia em branding, apoiada nos pilares da sustentabilidade, faz com que 
o consumidor da Whole Foods Market sinta-se mais saudável, consciente e engajado do que normalmente sentir-se-ia em uma compra qualquer de alimentos. O resultado disso pode ser visto no crescente lucro da empresa, na expansão do negócio e no impulso de seu valor de marca.

Em setembro de 2014, a empresa possuía em torno de 400 lojas nos EUA, Canadá e Inglaterra. Até 2017, a Whole Foods Market pretende expandir esse número para 500 lojas.

O sucesso da estratégia em branding da Whole Foods Market pode ser aferido pelos resultados de pesquisas globais recentes de acordo com Syncforce Ranking the Brands Top 100: em 2013, ocupou a 5a posição no ranking da Clear/M\&C Saatchi Group na Top 10 Desirable Retail Brands USA e a 80 posição no ranking da APCO Worldwide na The 100 most Loved Companies. Em 2014, ocupou a 13o posição no ranking da Intent $\mathrm{HQ}$ na The 25 Intent $\mathrm{HQ}$ Most Social Brands, a 20 o posição no ranking da Fortune na World's Most Admired Companies e a 230 posição no ranking da Interbrand na The Most Valuable U.S. Retail Brands.

\section{Ypê, sustentabilidade em algumas práticas e ações.}

A Ypê oferece produtos biodegradáveis e tem se destacado pelas iniciativas socioambientais. De acordo a empresa, sua missão é contribuir com a saúde e o bem -estar das pessoas, com produtos de higiene e limpeza práticos, eficientes e sustentáveis.

A Ypê busca um menor impacto possível no desenvolvimento de seus produtos, serviços e processos, atuando dentro dos parâmetros legais e ecologicamente corretos. Dentre suas principais iniciativas referentes à gestão ambiental, pode-se identificar a construção e a operação de um moderno sistema de tratamento de efluentes líquidos que faz o reuso de águas em seus processos internos.

Visando à conservação ambiental, a empresa iniciou, em 2007, uma parceria com a Fundação SOS Mata Atlântica no projeto Florestas Ypê, que tem como principal meta plantar milhares de árvores nativas, promovendo a restauração de áreas degradadas e, preferencialmente, daquelas que contribuem com a conservação da água e da biodiversidade.

No mesmo ano, lançou a nova logomarca atrelada à imagem de negócio que respeita o planeta. A mensagem da marca é "Cuidando bem da nossa casa", com o duplo sentido: o de produzir produtos que ajudem a limpar a casa, e por meio de suas preocupações socioambientais, cuidar do planeta.

Em 2008, a Ypê lançou o Ypê Premium, um sabão em pó com fórmula ecológica, livre de fosfato e sem custo adicional. Em 2012, a marca lançou a nova embalagem do produto lava-louça Ypê, uma embalagem de descarte sustentável, reciclável e biodegradável.

Visivelmente, a marca tem investido na ascensão do consumo consciente. A Ypê, percebendo uma tendência do consumidor a preferir produtos que oferecem bem-estar e respeitam o meio ambiente, tem investido na sustentabilidade empresarial como estratégia em branding.

A empresa possui foco e compromisso, investe em atitudes e processos susten- 
táveis que têm relação com o seu negócio e que agem com veracidade nas ações sustentáveis a que se propõem. A empresa valoriza a transparência das informações e disponibiliza no site da empresa um relatório para o acompanhamento do plantio do Projeto Floresta Ypê. Essas atitudes melhoram a reputação da empresa e aumentam a confiança no consumidor, elevando a marca a um posicionamento de ética e transparência.

A criação de produtos e serviços que atendam os desejos dos consumidores em qualidade, conveniência, custo-benefício e com menor impacto ambiental e social tem tornado a marca Ypê mais competitiva no mercado, em uma categoria de concorrência acirrada entre grandes multinacionais.

Os benefícios da sustentabilidade empresarial em branding têm elevando a marca na memória do consumidor e conquistado sua fidelidade. Os resultados desses esforços podem ser confirmados pelo crescimento de vendas e pelas pesquisas recentes expostas a seguir.

De acordo com dados de pesquisa da Nielsen, em 2013, a Ypê foi líder na categoria lava-louças, com quase $50 \%$ de market share. Segundo o ranking Brand Footprint, da Kantar Worldpanel, a Ypê foi a segunda marca em preferência e presença nos domicílios brasileiros, logo abaixo da Coca-Cola, mas ocupando o primeiro lugar na categoria higiene e limpeza.

Em 2014, a Ypê consagra-se como a marca de maior confiança na categoria de detergentes líquidos, ganhando pelo $12^{\circ}$ ano consecutivo o Prêmio Marcas de Confiança, pesquisa realizada pelo IBOPE para a Revista Seleções.

A Ypê foi eleita por oito anos consecutivos (2007 a 2014) como a primeira marca que vem à cabeça do brasileiro, na categoria Meio Ambiente, no prêmio Top of Mind, realizado pelo Instituto de Pesquisas Datafolha. 


\section{CONCLUSÃO}

O movimento de sustentabilidade cresce em escala mundial, visto que as preocupações com as questões sociais e ambientais são irreversíveis para a garantia de um futuro mais promissor. Os consumidores conscientes, além de identificarem os aspectos funcionais e emocionais dos produtos e serviços, passam cada vez mais a valorizar as práticas sustentáveis, desejam marcas com valores alinhados aos seus. A cadeia de valor não se restringe mais apenas às atividades produtivas da empresa, mas também as questões socioambientais.

As empresas são parte integrantes da sociedade e devem participar de forma responsável na solução dos problemas socioambientais existentes. Uma empresa sustentável deve investir em inovação; melhorar o bem estar de seus funcionários e consumidores; investir em práticas sociais; se preocupar com a gestão sustentável em toda a sua cadeia e com o ciclo de vida de seus produtos bem como buscar reduzir ao mínimo o seu impacto. Quando isso não for possível, deve compensar suas "pegadas" com ações efetivas. A nova demanda da sociedade não significa necessariamente impacto zero ao planeta. O que os consumidores esperam é que esse impacto seja o menor possível e que o discurso seja coerente com suas ações. Por tudo isso, as marcas precisam alinhar suas ações com o seu propósito, a sua missão e os seus valores.

As marcas sustentáveis são valorizadas pelo seu compromisso verdadeiro, por sua autenticidade e ética. Elas passam a ter um significado especial e valores compartilhados com seus consumidores, gerando um aumento de sua reputação e fidelização dos clientes. Quando o consumidor cria um vinculo de confiança com a marca, ele deposita toda a sua expectativa de boas condutas e ações porque acredita naquela marca e, mais do que isso, identifica-se com o seu propósito.

A aplicação da sustentabilidade alinhada ao corebusiness da empresa exige comprometimento e empenho. Dessa forma, a marca ganha confiança e credibilidade, diferenciais significativos no mercado atual, que podem garantir a perenidade de uma empresa. Nesse entendimento, a sustentabilidade é importante porque gera lucro e valorização da marca.

As empresas analisadas nesse estudo, a Whole Foods e a Ypê, demonstraram ter práticas de sustentabilidade reais, significativas e mensuráveis. Ambas as empresas se utilizam da sustentabilidade como vantagem competitiva em branding, possuem apelo emocional sustentado por informações funcionais, comunicam-se de forma clara e objetiva, são comprometidas com os seus valores e são autênticas, agindo de acordo com o seus discursos.

Concluindo, as análises teóricas, na perspectiva da estratégia de sustentabilidade em branding, indicam que essa estratégia pode ser um diferencial competitivo valioso, bem como uma oportunidade nesse mercado de concorrência acirrada e de produtos e serviços similares. Se praticada de forma eficiente, pode resultar em um forte propósito, lucratividade, relevância, reputação e valor para a marca, questões fundamentais para o crescimento e perenidade das empresas.

Comparando as duas empresas estudadas, a Whole Foods Market, tem a sustentabilidade como propósito principal do seu negócio, incorporada à sua estratégia e 
ao seu modelo de negócio. Por outro lado, a Ypê tem melhorado alguns processos fabris e produtos de seu portfolio ao mesmo tempo em que investe em sua imagem de marca sustentável.

Este estudo suscita a necessidade de investigar a influência das diferentes práticas de sustentabilidade em branding. A questão principal que nasce desse artigo é o quão sustentável precisa ser uma empresa para começar a gerar valor e ser competitiva em branding? Qual a vantagem significativa de uma empresa com um propósito sustentável sobre outra que tem apenas algumas práticas sustentáveis, quando ambas são autênticas? Alguma das estratégias garante mais atratividade, fidelidade e confiança?

\section{REFERÊNCIAS BIBLIOGRÁFICAS}

ALMEIDA, F. O bom negócio da sustentabilidade. Rio de Janeiro: Nova Fronteira, 2002. 190p.

BARBIERI, J. C. et al. Inovação e Sustentabilidade: Novos Modelos e Proposições. Revista de administração de empresas RAE/FGV, v.50, n.2, p.146-154, abr./jun. 2010.

BARBIERI, J. C.; CAJAZEIRA, J. E. R. Responsabilidade social empresarial e empresa sustentável: da teoria à prática. São Paulo: Editora Saraiva, 2009. 230p.

BRUNDTLAND, G. et al. Our Common Future: The World Commission on Environment and Developmen. New York: ONU, 1987. 300p.

CASTELLS, M. O poder da identidade. São Paulo: Paz e Terra, 1999. 530p.

ELKINGTON, J. Cannibals with Forks: The Triple Bottom Line of 21st Century Business. Oxford, Capstone Publishing, 1997. 407p.

FOLHA DE SÃO PAULO. Top of Mind: Datafolha revela as marcas mais lembradas no Brasil. Folha de São Paulo, São Paulo, 27 out. 2014. Disponível em: <http://www1. folha.uol.com.br/topofmind/2014/10/1529283-top-of-mind-datafolha-revela-asmarcas-mais-lembradas-no-brasil.shtml> Acesso em: 19 out. 2015.

HARTMANN, P.; APAOLAZA IBÁÑEZ V.; FORCADA SAINZ, F. J. Green branding effects on attitude: functional versus emotional positioning strategies. Marketing Intelligence \& Planning, v.23, n.1, p.9-29. 2005.

HOLT, D. B. Why do brands cause trouble? A dialectical theory of consumer culture and branding. Journal of Consumer Research, Oxford University Press, v.29, n.1, p.7090. Jun. 2002. 
IBOPE INTELIGÊNCIA. Pesquisa Marcas de Confiança 2015. Disponível em: < http:// www.selecoes.com.br/marcasdeconfianca> Acesso em: 20 out. 2015.

INSTITUTO AKATU. Estilos sustentáveis de vida. Resultados de uma pesquisa com jovens brasileiros. Instituto Akatu, 2009. 40 p. Disponível em: <http://www.akatu.org. br/ Content/Akatu/Arquivos/file/Publicacoes/EstilosSustentaveisdeVida.pdf>. Acesso em: 10 fev. 2015.

INSTITUTO ETHOS DE EMPRESAS E RESPONSABILIDADE SOCIAL. Princípios e compromissos. Disponível em: <http://www3.ethos.org.br/>. Acesso em: 20 jan. 2015.

KANTAR WORLDPANEL. Top 50 das marcas mais escolhidas pelo consumidor. 2014. Disponível em: http://www.kantarworldpanel.com/br Acesso em: 30 jan. 2015.

KAPFERER, J. N. Strategic Brand Management. New York: Free Press, 1992. 341p.

KOTLER, P.; KARTAJAYA, H.; SETIAWAN, I. Marketing 3.0: as forças que estão definindo o novo marketing centrado no ser humano. Rio de Janeiro: Elsevier, 2010. 215p.

LEHNER, M.; HALLIDAY, S. V. Branding sustainability: Opportunity and risk behind a brand-based approach to sustainable markets. Ephemera Journal, v.14, n.1, p.13-34. 2014.

MANZINI, E. Design, Ethics and Sustainability - Guidelines for a Transition Phase. Milan: Politenico di Milano, 2006. 8p.

MARTINS, J. R. Branding: Um manual para você criar, avaliar e gerenciar marcas. São Paulo: Globalbrands, 2006. 312p.

MCCONNELL, R. Edelman: Consumers will pay up to support socially conscious marketers. Advertising Age, 2007. 2p. Disponível em <http://adage.com/article/news/ edelman-consumers-pay-support-socially-conscious-marketers/122084/> Acesso em: 12 jan. 2015.

PINHEIROS, M. D. Ambiente e Construção Sustentável. Lisboa: Instituto do Ambiente, 2006. 240p.

PRINGLE, H.; THOMPSON, M. Marketing social: marketing para causas sociais e a construção das marcas. São Paulo: Makron Books, 2000. 258p.

REDAÇÃO PORTAL IMPRENSA. Ypê estréia nova campanha brincando com o volume de vendas da marca. Portal Imprensa, 30 set. 2013. Disponível em: < http://portalimprensa.com.br/cdm/caderno+de+midia/61478/ype+estreia+nova+campanha+brincando+com+o+volume+de+vendas+da+marca> Acesso em: 19 out. 2015. 
SACHS, I. Caminhos para o Desenvolvimento Sustentável. Rio de Janeiro: Garamond, 2002. 95p.

UNDSD - United Nations Division for Sustainable Development. Agenda 21. Rio de Janeiro: United Nations Conference on Environment \& Development, 1992. 475p.

SYNCFORCE RANKING THE BRANDS TOP 100. Disponível em: <http://www.rankingthebrands.com/> Acesso em: 30 jan. 2015.

WHOLE FOODS GREEN MISSION REPORT. 2012. 59p. Disponível em: <http://www. wholefoodsmarket.com_sites_default_files_media_Global_PDFs_2012GreenMissionReport> Acesso em: 20 dez. 2014.

YPÊ. Sobre a Ypê. Disponível em: <http://www.ype.ind.br/> Acesso em: 25 jan. 2015. 